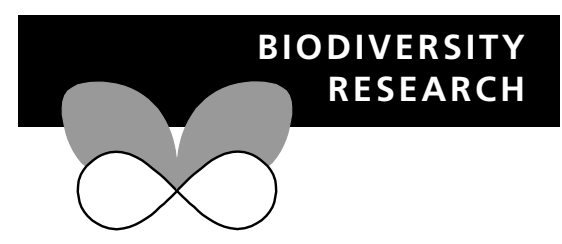

\title{
In situ hatching of invertebrate diapausing eggs from ships' ballast sediment
}

Sarah A. Bailey ${ }^{1 \star}$, Kanavillil Nandakumar ${ }^{1} \dagger$, Ian C. Duggan ${ }^{1} \ddagger$, Colin D. A. van Overdijk $^{1}$, Thomas H. Johengen ${ }^{2}$, David F. Reid ${ }^{3}$ and Hugh J. MacIsaac ${ }^{1}$

${ }^{1}$ Great Lakes Institute for Environmental Research, University of Windsor, Windsor, ON, N9B 3P4, Canada, ${ }^{2}$ Cooperative Institute for Limnology and Ecosystems Research/University of Michigan, Ann Arbor, MI, 48104-2298, USA; and ${ }^{3}$ National Oceanic and Atmospheric Administration/Great Lakes Environmental Research Laboratory, Ann Arbor, MI, 481052945, USA
${ }^{*}$ Correspondence: Sarah A. Bailey, Great Lakes Institute for Environmental Research, University of Windsor, Windsor, ON, N9B 3P4, Canada. Tel.: (519) 253-3000 ext 2734,

Fax: (519) 971-3616,

E-mail: sarahbailey@canada.com

$\dagger$ Present address: Biology Department, Lakehead University, Thunder Bay, ON, P7B 5E1, Canada. $\ddagger$ Present address: Centre for Biodiversity and Ecology Research, Department of Biological Sciences, University of Waikato, Hamilton, New Zealand.

\begin{abstract}
Ships that enter the Great Lakes laden with cargo carry only residual ballast water and sediment in ballast tanks. These ships are designated 'no ballast on board' (NOBOB) and constitute $>90 \%$ of inbound traffic. We conducted in situ experiments using emergence traps to assess the viability and the introduction potential of invertebrate diapausing stages present in ships' ballast sediment. All trials commenced while vessels operated on the lower lakes (Erie, Ontario) and were completed 6-11 days later at ports on the upper lakes (Michigan, Lake Superior). Eight trials were conducted on four ships using five different ballast sediments. Hatching was observed on every ship, although not from all sediments on all ships. Overall hatch rates were very low ( 0.5 individuals per $500 \mathrm{~g}$ sediment), typically involving activation of $<0.05 \%$ of total eggs present. Five species of rotifers and copepod nauplii were hatched from ballast sediments, although only one or two species typically hatched from any one sediment. Results of this study indicate that hatching of diapausing eggs contained in ballast sediment of $\mathrm{NOBOB}$ ships poses a relatively low risk of invasion to the Great Lakes. However, as reproduction may occur in tanks, and non-indigenous species may be involved in numerous introduction events, the risk posed by this vector is small but potentially important. While dormancy is a characteristic enabling enhanced survival during transportation in ballast tanks, it becomes a hindrance for introduction.
\end{abstract}

\section{Keywords}

Ballast water, biological invasions, Great Lakes, introduction, non-indigenous species, resting stages.

\section{INTRODUCTION}

Early attempts to understand and predict biological invasions typically consisted of qualitative assessments of species or community characteristics drawn from case studies of successfully established introduced species or invaded ecosystems (Elton, 1958; see review by Lodge, 1993). General patterns elucidated during this research provided a framework for the development of invasion theory, although few of the studies were quantitative or experimental and most failed to consider alternative explanations for observed patterns (Lodge, 1993; Kolar \& Lodge, 2001; Colautti \& MacIsaac, 2004). Recent studies designed to identify life history differences between successful and unsuccessful invasions of non-indigenous species (NIS) have focused on the stage of the invasion (e.g. Wonham et al., 2000; Kolar \& Lodge, 2001, 2002). These studies recognize that successful invasions encompass a series of different stages including transport, introduction, establishment, and, in some cases, spread. Because uptake and transportation by a vector are the earliest stages in the sequence, efforts have been made to link introduction effort or 'propagule pressure' to invasion success (Veltman et al., 1996; Duncan et al., 2003; Rouget \& Richardson, 2003; see also Colautti et al., 2005). Introduction effort has two components, the inoculant size for a given introduction event and the frequency of inoculation events (see Kolar \& Lodge, 2001; Colautti \& MacIsaac, 2004). Although not widely tested in aquatic ecology, available evidence generally supports the propagule pressure hypothesis (Colautti et al., 2005).

Ship-mediated vectors such as hull fouling, ballast water and sediments are regarded as principal pathways for unintentional introductions of aquatic organisms worldwide (e.g. Carlton, 1985; Ruiz et al., 2000; Grigorovich et al., 2002, 2003; Leppäkoski et al., 2002; Hayes \& Sliwa, 2003). Organisms may be introduced by ship-mediated vectors if they can survive the physical, chemi$\mathrm{cal}$, and biological rigours associated with uptake and discharge 


\section{S. A. Bailey et al.}

Table 1 Summary of transit dates and locations for onboard ship experiments. Two trials were run inside the same tank of each ship. Average temperature \pm SD, as measured from near tank bottom, was calculated from three to four points of time across voyage. Tank types: FP — forepeak, UW - upper wing tank, and DB — double-bottom. Number of traps column lists number of experimental replicates (E), negative (N), positive $(\mathrm{P})$, and live (L) control traps for each sediment type. Traps excluded from analysis are also excluded here

\begin{tabular}{|c|c|c|c|c|c|c|}
\hline Voyage & Start location & End location & Tank type & $\begin{array}{l}\text { Average } \\
\text { temp. }\left({ }^{\circ} \mathrm{C}\right)\end{array}$ & Sediment & $\begin{array}{l}\text { No. of traps } \\
(\mathrm{E}, \mathrm{N}, \mathrm{P}, \mathrm{L})\end{array}$ \\
\hline \multirow[t]{2}{*}{1} & Windsor, ON & Milwaukee, WI & FP & $16.5 \pm 1.6$ & A & $5,1,0,0$ \\
\hline & October 5, 2002 & October 11, 2002 & & & B & $4,1,0,1$ \\
\hline \multirow[t]{2}{*}{2} & Hamilton, ON & Thunder Bay, ON & UW & $20.6 \pm 2.6$ & A & $4,1,1,1$ \\
\hline & July 2, 2003 & July 13, 2003 & & & $\mathrm{C}$ & $5,1,1,1$ \\
\hline \multirow[t]{2}{*}{3} & Hamilton, ON & Milwaukee, WI & UW & $20.4 \pm 2.1$ & B & $6,1,1,1$ \\
\hline & July 14, 2003 & July 24, 2003 & & & $\mathrm{C}$ & $6,1,1,1$ \\
\hline \multirow[t]{2}{*}{4} & Cleveland, $\mathrm{OH}$ & Duluth, MN & $\mathrm{DB}$ & $18.4 \pm 5.4$ & $\mathrm{D}$ & $6,1,1,1$ \\
\hline & September 15, 2003 & September 26, 2003 & & & E & $5,1,1,1$ \\
\hline
\end{tabular}

of ballast water, in addition to long-distance transport (Carlton, 1985). Studies of ballast water invasions by non-indigenous invertebrates to the Great Lakes have suggested that the ability of species to form dormant or diapausing life stages should enhance survivability through the transportation stage (stage I, sensu Colautti \& MacIsaac, 2004; Holeck et al., 2004). Analysis of the invasion history of the Great Lakes since 1959 confirmed that 15 of 19 NIS of crustaceans that successfully invaded are able to produce resting or diapausing stages (Bailey et al. in review). However, the dense nature of residual ballast sediments combined with their propensity for accumulation in tanks, suggests that diapausing stages within sediments may not ordinarily be expelled from tanks during normal operation. Thus, the ability of diapausing stages to transition directly from transportation (stage I) to introduction (stage II) is probably quite limited. A much more likely mechanism for introduction of NIS from residual sediment consists of hatching of viable diapausing eggs while the ship is in ballast, followed by discharge of planktonic taxa during deballasting operations. Standard operations of 'no ballast on board' (NOBOB) vessels may induce hatching of diapausing eggs when ships visit multiple ports in the Great Lakes (Bailey et al., 2003). These vessels enter the system loaded with cargo and carry only residual water and sediment in ballast tanks. NOBOB vessels load Great Lakes' water as ballast to maintain vessel trim and stability after offloading cargo, usually at ports on the lower lakes (Colautti et al., 2003). Bailey et al. (2003) proposed that the uptake of oxygenated fresh water may stimulate diapausing eggs in ballast sediments to hatch, facilitating release of planktonic taxa when the mixed ballast water was discharged at the last port-of-call, typically in Lake Superior (Colautti et al., 2003).

All experiments conducted to date on viability of invertebrate resting stages in ballast sediments have been performed in the laboratory under controlled conditions (Bailey et al., 2003, 2004; Gray et al., 2005). Here we seek to estimate the number of propagules passing through the introduction phase (stage II), with in situ studies on hatching by diapausing eggs contained within residual sediments of transoceanic ships operating on the Great Lakes. Specifically, we deployed a series of emergence traps con- taining defined ballast sediment within ballast tanks of operational vessels to determine if diapausing eggs could be induced to hatch with the addition of Great Lakes water to ballast tanks.

\section{METHODS}

Use of emergence traps in ballast tanks allows for incubation of diapausing eggs under conditions closely approximating those of the ballast tanks. Through careful deployment of control traps, it is possible to differentiate individuals hatched from ballast sediments from contaminants in the tanks, and to determine whether conditions were suitable for aerobic species. Experiments using emergence traps were conducted on four ships in October 2002 and in July and September 2003 (Table 1). Two trials were conducted inside the same tank on each ship, each using a different ballast sediment. Five sediments were used for the eight trials. Candidate sediments were collected in December 2001, June 2002 and in June and July 2003 from individual ballast tanks of NOBOB ships operating on the Great Lakes (methodology as in Bailey et al., 2003). Sediments used here were selected on the basis of high egg density to maximize opportunities for hatching of diapausing eggs (see Bailey et al., 2005 for distribution of egg densities found in ballast sediments). Subsamples of each sediment were removed to characterize the density and diversity of diapausing eggs in the laboratory before usage of sediments in emergence trap experiments (see Bailey et al., 2005 for laboratory methods). Sediments were stored in the dark at $4{ }^{\circ} \mathrm{C}$ until the onset of in situ trap experiments, allowing a minimum of 3 weeks for a refractory period.

\section{Trap design and deployment}

Simple, low-cost emergence traps were constructed from standard polyvinyl chloride (PVC) plumbing components to monitor in situ hatching of diapause eggs from residual ballast sediments. Emergence traps were designed to allow ballast water to flow through each experimental chamber, while excluding organisms present in the surrounding water and retaining what hatched inside traps. Each emergence trap was built from a 15-cm (interior 


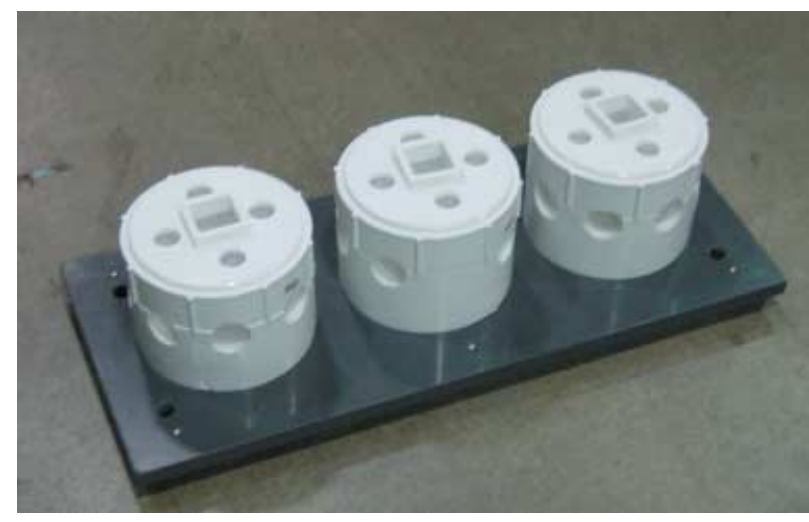

Figure 1 Three emergence traps bolted to PVC platform. Holes in lids and sides of traps are covered with $53 \mu \mathrm{m}$ Nitex plankton mesh. Holes at platform corners were used to secure traps to ballast tank's internal structure.

diameter) pipe cap with a threaded lid, having a surface area of approximately $180 \mathrm{~cm}^{2}$. Bolts were put through the bottom of the pipe cap to secure the trap to a rectangular PVC platform and sealed with silicone glue (Fig. 1). Twelve holes of approximately $2.5-4 \mathrm{~cm}$ diameter were drilled through the lid and wall of each trap, and were subsequently covered with Nitex plankton mesh (mesh sizes given in succeeding discussion). Mesh was attached to the interior surface of the trap housing using clear PVC cement and edges were sealed with silicone glue. After construction, traps were left to cure for $48 \mathrm{~h}$ and were subsequently rinsed with deionized water to remove any coarse debris and soluble compounds left by the glues.

Trap platforms, each carrying three linearly spaced emergence traps, were secured to the bottom surface of the ballast tank using cable ties threaded through drainage holes in the ballast tank's internal structure. After all the platforms were moored, each trap was loaded with $500 \mathrm{~g}$ residual ballast sediment (approximately $2 \mathrm{~cm}$ in depth) and the trap lids were secured. After our crew exited the tanks, ballast water was loaded into the tanks such that all traps were submerged. Ships thereafter resumed normal operation and offloaded cargo at one to three additional ports before discharging all ballast water and loading outbound cargo at the final port-of-call. Zooplankton composition of ballast water during transit was monitored by collecting three replicate net hauls of approximately 100-400 L volume, using a 0.25 m-diameter, $30-\mu \mathrm{m}$ plankton net preserved in $95 \%$ ethanol. Net samples were taken inside ballast tanks immediately after traps were submerged and at two or three subsequent ports, including the final port before ballast was discharged. Each net sample was later scanned under a dissecting microscope and representative taxa were identified with a compound microscope at up to $1000 \times$ magnification. In addition, temperature readings were measured near tank bottom at all ports where net samples were drawn using a Hydrolab DataSonde 4a.

On the initial ship, traps were constructed using $34 \mu \mathrm{m}$ Nitex mesh. Six traps were used for each of two sediment types. One trial consisted of five experimental replicates (precharacterized sediment), and had a negative control trap (autoclaved sediment) to monitor for the introduction of species from the ship's ballast water. The second trial had four experimental replicates and negative and live control traps. The latter trap contained the same non-autoclaved sediment as was used for the experimental replicates, where 40 oligochaetes, Lumbriculus variegatus (Müller), and 40 amphipods, Hyalella azteca (Saussure), were added. These species served as sentinels of sediment toxicity and anoxia in the traps (e.g. Sprague, 1963; Putzer et al., 1990; Dermott \& Munawar, 1992; Nebeker et al., 1992; Phipps et al., 1995).

The experimental design was modified slightly for all subsequent trap experiments to improve waterflow through traps, and to increase statistical power. These experiments used traps with $53 \mu \mathrm{m}$ mesh, and six experimental replicates per trial. Each trial had its own negative and live controls, the latter containing $20 \mathrm{~L}$. variegatus and $20 \mathrm{H}$. azteca. In addition, a positive control was included for each trial, consisting of diapausing eggs isolated from $500 \mathrm{~g}$ sediment using a sugar flotation protocol (Bailey et al., 2003), which served to assess whether hatching and survival of taxa were similar with and without sediment. Prior laboratory experiments illustrated that diapausing eggs had higher hatch rates when separated from sediments (Bailey et al., 2005). A lack of hatching in this control trap would highlight possible toxicity effects associated with the sediment, or other inhospitable conditions inside the trap. Conversely, the presence of hatching in positive controls, when hatching is absent in experimental replicates, would indicate effects associated with burial of eggs in sediment.

\section{Trap recovery and analysis}

Traps were recovered at the terminal port-of-call after ballast water had been discharged. Approximately $450 \mathrm{ml}$ of water, which remained inside traps below the drainage holes, was collected by large-mouth pipette and filtered through $30 \mu \mathrm{m}$ mesh. The filtrate was preserved using 95\% ethanol for later enumeration and identification of invertebrate taxa. Sediment was subsequently recovered from each trap and preserved in 95\% ethanol. Taxa associated with the sediment were isolated for enumeration and identification using the colloidal silica Ludox ${ }^{\circledR}$ HS40 (Burgess, 2001). Negative and positive controls were recovered and analysed in the same manner except that the Ludox method was only required for negative controls. After recovery, all emergence traps were inspected for integrity. Four experimental replicates were excluded from analysis because of visible tears in plankton mesh. Live traps were surveyed to determine the number of oligochaetes and amphipods that remained alive.

For enumeration of hatched taxa, any taxa recovered from emergence traps that do not possess diapausing stages (e.g. bdelloid rotifers, bivalves) or mature forms that could not have developed within the transit timeframe (e.g. copepodids) were excluded from analyses as these organisms were likely introduced with the sediment at the onset of the experiment. In addition, analysis of negative controls indicated that some organisms present in the Great Lakes ballast water had infiltrated the plankton mesh on emergence traps. As a result, all taxa present in either negative control for each ship were subtracted from results 


\section{S. A. Bailey et al.}

of experimental replicates. Furthermore, to be conservative, any recovered taxa not identified during laboratory experiments using the same sediments (under ideal growth conditions) were excluded from analysis. Our analyses are, therefore, based on conservative estimates of in situ hatch rates and may underestimate actual richness and abundance of hatched taxa. Total abundance of organisms hatched from in situ experimental replicates was compared to that of laboratory characterization experiments using a Mann-Whitney $U$-test (systat 8.0, SPSS, Inc., 1998). Because laboratory experiments were conducted using only $40 \mathrm{~g}$ (as opposed to $500 \mathrm{~g}$ ) sediment replicates, total abundances of hatched species were extrapolated to $500 \mathrm{~g}$ before analysis. We also compared species richness of laboratory and in situ hatch rates using a Mann-Whitney $U$-test.

\section{Estimation of inoculum size}

To determine the risk of introduction posed by invertebrates hatched from diapausing eggs carried by transoceanic vessels, we calculated the average rate of hatching per $500 \mathrm{~g}$ replicate for the eight in situ trials. This rate was used to estimate the number of individuals hatching across an entire ship, given that a single ship typically carries 10-15 tonnes of residual sediment (Bailey et al., $2003,2005)$. As hatching rate may be affected by surface area, we also produced estimations based on surface area of traps, scaled by surface area of residual sediment across a ship, using the assumption that residual sediment is uniformly distributed across the ship hull at a depth of $2.5 \mathrm{~cm}$. Finally, we used occurrence and abundance of NIS recorded from previous ballast sediment characterization studies to estimate the typical inoculum size for taxa that would pose an invasion threat to the Great Lakes.

\section{RESULTS}

Emergence traps remained submerged for 6-11 days, depending on ship schedule. Water temperature near the bottom of ballast tanks ranged widely, primarily because of season and storm events, with average temperatures during voyages ranging between $16.5^{\circ} \mathrm{C}$ and $20.6{ }^{\circ} \mathrm{C}$ (Table 1). A fraction of live control animals were not recovered at the end of the first three experiments as a result of procedural errors during processing. However, 100\% of live control animals were recovered after the fourth and final in situ experiments. All live control animals that were recovered were alive, indicating that environmental conditions within traps were sufficient to support life for the duration of each voyage. Nineteen individuals were hatched from 41 experimental replicates, producing an average hatching abundance of $0.5(\mathrm{SD}=1.0)$ individuals per $500 \mathrm{~g}$ replicate (Table 2). Hatching occurred in six of eight trials. Both trials without hatching occurred on separate ships; thus hatching occurred in at least one experimental replicate on every ship. Species that hatched included the rotifers Brachionus calyciflorus Pallas, Cephalodella catellina (Müller), Keratella tecta (Gosse), Synchaeta oblonga Ehrenberg, and Trichocerca pusilla (Lauterborn), and copepod nauplii (Table 2). None of the individuals recovered from experimental replicates were observed in a reproductive condition.
Table 2 Summary of hatching results for in situ emergence trap experiments. Egg density is average number \pm SD of diapausing eggs per $500 \mathrm{~g}$ sediment placed in traps at the start of voyage. Hatching success gives mean \pm SD number of individuals hatched per successful experimental replicate ( $n$ in parentheses). Positive control lists number of individuals hatched from single replicate with isolated eggs; ${ }^{*}$ indicates presence of adult females carrying parthenogenetic eggs

\begin{tabular}{|c|c|c|c|c|}
\hline Voyage & Species hatched & Egg density & $\begin{array}{l}\text { Hatching } \\
\text { success }\end{array}$ & $\begin{array}{l}\text { Positive } \\
\text { control }\end{array}$ \\
\hline \multirow[t]{5}{*}{1} & Sediment A & $1114 \pm 103$ & & \\
\hline & Brachionus calyciflorus & & $1(1)$ & $\mathrm{n} / \mathrm{a}$ \\
\hline & Copepod nauplii & & $1(2)$ & $\mathrm{n} / \mathrm{a}$ \\
\hline & Sediment B & $1840 \pm 385$ & & \\
\hline & No hatching & & 0 & $\mathrm{n} / \mathrm{a}$ \\
\hline \multirow[t]{8}{*}{2} & Sediment A & $1114 \pm 103$ & & \\
\hline & B. angularis & & 0 & 1 \\
\hline & B. budapestinensis & & 0 & 1 \\
\hline & B. calyciflorus & & $1(1)$ & 9 \\
\hline & Sediment C & $538 \pm 81$ & & \\
\hline & B. budapestinensis & & 0 & 1 \\
\hline & B. calyciflorus & & 0 & 13 \\
\hline & B. diversicornis & & 0 & 1 \\
\hline \multirow[t]{9}{*}{3} & Sediment B & $1840 \pm 385$ & & \\
\hline & B. angularis & & 0 & $38^{*}$ \\
\hline & B. calyciflorus & & 0 & $51^{*}$ \\
\hline & Cephalodella catellina & & $1(1)$ & 0 \\
\hline & Synchaeta oblonga & & $1 \pm 0.6(3)$ & 0 \\
\hline & Trichocerca pusilla & & $1 \pm 0$ & 0 \\
\hline & Sediment C & $538 \pm 81$ & & \\
\hline & Copepod nauplii & & $1(1)$ & 9 \\
\hline & Trichocerca stylata & & 0 & 2 \\
\hline \multirow[t]{9}{*}{4} & Sediment D & $2966 \pm 276$ & & \\
\hline & B. angularis & & 0 & 10 \\
\hline & B. budapestinensis & & 0 & 1 \\
\hline & B. diversicornis & & 0 & 1 \\
\hline & B. calyciflorus & & $5(1)$ & $1073^{*}$ \\
\hline & Sediment E & $1605 \pm 80$ & & \\
\hline & B. angularis & & 0 & $59^{*}$ \\
\hline & B. calyciflorus & & 0 & $289^{*}$ \\
\hline & Keratella tecta & & $2(1)$ & 2 \\
\hline Total & & & $19(13)$ & 1561 \\
\hline
\end{tabular}

Diapausing eggs were not as likely to hatch in situ as under laboratory conditions. Both total abundance and species richness of organisms hatched were significantly lower in situ than in laboratory characterization trials (Mann-Whitney $U$-test, $P<0.001$; Fig. 2). Also, the effect of burial had a significant impact on the number of eggs that hatched (Mann-Whitney $U$-test, $P<0.001$; Fig. 3), although this could only be tested for the laboratory experiments as positive controls on ships were not replicated.

Hatching also occurred in all six positive controls, supporting the hypothesis that abiotic conditions in ballast tanks were favourable and that hatching was inhibited in experimental replicates by some factor associated with the sediment. In total, 


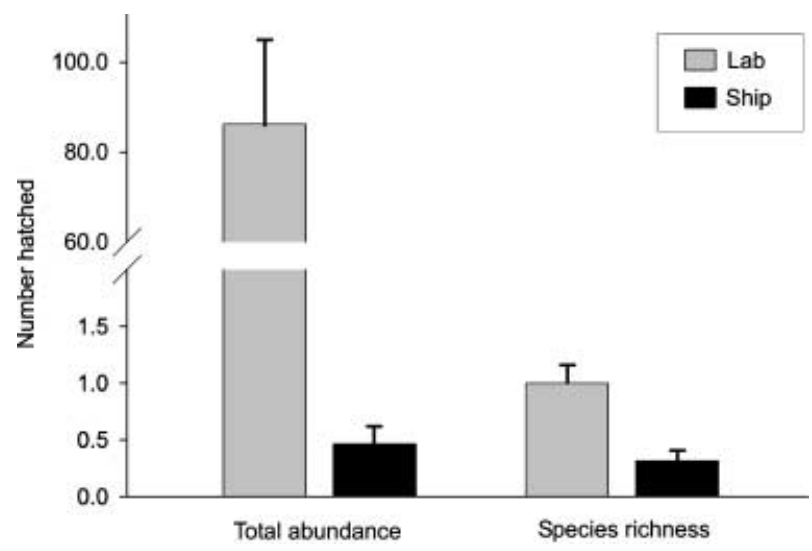

Figure 2 Total abundance and species richness of taxa hatched from residual ballast sediments in laboratory and ship studies. Total abundance is number of individuals hatched per $500 \mathrm{~g}$ sediment for both laboratory and ship experiments, whereas species richness is number of taxa hatched per 40 and 500 g sediment for laboratory and ship experiments, respectively. Note scale break in $y$-axis.

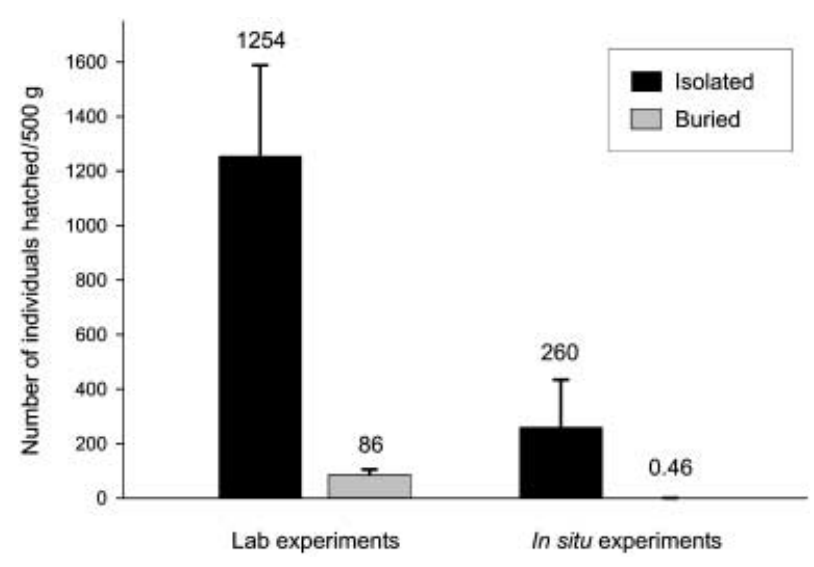

Figure 3 Total abundance of taxa hatched in laboratory and ship studies from diapausing eggs isolated from, or buried in, five residual ballast sediments.

1561 individuals were recovered from positive controls (mean $260 \pm 425$ ), although this number likely included parthenogenetic offspring (see Table 2). Species hatched in positive controls include the rotifers Brachionus angularis Gosse, Brachionus budapestinensis Daday, Brachionus calyciflorus, Brachionus diversicornis (Daday), Keratella tecta and Trichocerca stylata (Gosse), and copepod nauplii (Table 2).

\section{Estimation of inoculum size}

The rate of hatching recorded during this study ranged from $0.01 \%$ to $0.04 \%$. Extrapolations based on sediment volume and surface area suggest the sediments used in these experiments could release approximately 7000-15,000 individuals per ship under similar environmental conditions (typically June-October). However, previous work suggests that only approximately $2.5 \%$ of resting stages transported in residual sediments are from species nonindigenous to the Great Lakes (Bailey et al., 2005). Consequently, the inoculum size of NIS introduced via this vector is probably much lower than the total number estimated by the present study, at 175-375 non-indigenous individuals per ship. Furthermore, as ships with non-indigenous taxa present typically carry one or two NIS each (S.A. Bailey, unpublished data), this may result in an inoculum size of only 87-375 individuals per taxon.

\section{DISCUSSION}

Previous studies estimate that only a small proportion (approximately $10 \%$ ) of invaders will survive passage from the transportation stage to the introduction stage, with most organisms dying in transit (Carlton, 1985; Williamson \& Fitter, 1996; Kolar \& Lodge, 2001). However, diapausing eggs likely enhance survivability of invertebrates during transportation, with up to $92 \%$ of eggs collected from residual sediments being viable in laboratory studies (Bailey et al., 2003). But does this mechanism that increases survival during the transportation stage facilitate successful introduction? With the use of in situ emergence trap experiments, we were able to demonstrate that diapausing eggs can hatch from sediments inside ballast tanks of operational ships, albeit at very low rates.

Although all of the species hatched in these in situ trials are cosmopolitan and appear to pose little or no invasion risk, they could pose a risk for genetic invasion, as many plankton species differ genetically between continents. However, as shipping activities have been translocating thousands of species for hundreds of years, the broad geographical distributions of many taxa today may actually be the result of earlier introductions (Carlton, 1985, 2003; Gollasch et al., 2002). Nonetheless, the NIS Brachionus diversicornis was hatched from positive controls on two voyages, confirming that NIS with restricted distributions are present as diapausing eggs at extremely low abundance (see Bailey et al., 2005). The fact that B. diversicornis was not hatched from experimental replicates may be a result of the small volumes of sediment used. Conversely, burial in sediment may have precluded hatching cues from inducing hatching in this species.

Only 0.5 diapausing eggs hatched per $500 \mathrm{~g}$ replicate during these experiments. This value is less than $0.05 \%$ of the total number of eggs present in the experimental sediments. Despite the fact that NOBOB vessels typically carry 10-15 tonnes of sediment, the probability that NIS will be present and receive hatching cues is small. This gives an estimated inoculum size of 87-375 individuals per taxa. Furthermore, as the sediments used in this study were selected for high egg density, this is likely a greater inoculum than that presented by most ships entering the system.

Propagule pressure is based not only on the inoculum size, but also on the frequency of inoculations. Approximately 250 NOBOB vessels conduct multiport operations on the Great Lakes each year that may provide conditions for hatching and introduction of resting stages (Colautti et al., 2003). Approximately $32 \%$ of these vessels will carry resting stages of NIS (Bailey et al., 2005), providing a frequency of approximately 80 inoculations per year. This translates to approximately $5.7 \times 10^{3}-3.0 \times 10^{4}$ 


\section{S. A. Bailey et al.}

non-indigenous individuals introduced via the residual sediment vector per year. Considering that a single NOBOB vessel may introduce $10^{5}$ individuals of NIS via residual ballast water (Duggan et al. in review), the relative importance of diapausing stages in sediments appears much lower.

As the prolonged existence of temporal zooplankton is dependent on the formation of a sexually produced diapausing egg bank, Allee effects (i.e. zero or negative growth of small populations owing to density-dependent population dynamics) may impact establishment success of non-indigenous zooplankton introduced to the Great Lakes. However, in a modelling exercise, Drake (2004) estimated that inoculum sizes as small as 10 parthenogenetic individuals may result in successful establishment if given enough time to produce a large population before the onset of sexual reproduction. Activities of $\mathrm{NOBOB}$ vessels seem to fit the optimum release strategies calculated for terrestrial biological control insects by participating in numerous, small-sized release events (as discussed in Grevstad, 1999). Furthermore, as ballast-mediated introduction events are spread out over both time and space, risks associated with environmental stochasticity will be reduced, indicating that the small inoculum sizes suggested by this study may not be insignificant.

During the course of this study, we recorded one individual of the NIS Brachionus leydigi Cohn from the Great Lakes' ballast water loaded on voyage 2 . This species has been observed as a rare component of diapausing egg fauna in residual ballast sediments of previous studies (Bailey et al., 2005). However, as residual sediments generally do not accumulate in upper wing tanks, this individual probably did not hatch from sediments within the tank but may be the result of a previous introduction to Hamilton Harbour from ballast discharge by a transoceanic vessel. As only one individual was recovered from plankton samples, we cannot determine whether the species has established in Hamilton Harbour. However, this finding may be an indication that introductions of NIS of rotifers may already have occurred.

We have not adjusted inoculum size for increases due to reproduction as there was no evidence of reproduction by the individuals hatched in experimental replicates during this study. Reproduction rates of parthenogenetic taxa are affected by numerous factors, such as temperature, food quantity and quality, and genetic composition (Wallace \& Snell, 2001). Assuming exponential growth (Taylor, 1988) and published life history parameters for B. calyciflorus at $16-20{ }^{\circ} \mathrm{C}$ (Pourriot \& Rougier, 1997; Wallace \& Snell, 2001), we determined that 15-45 individuals may have been the founding (hatching) population size for the 1073 individuals recovered from the positive control during voyage 4 . The occurrence of reproduction in positive control replicates during voyages 3 and 4 suggests that ballast tanks can provide suitable conditions for parthenogenetic reproduction, at least during warmer months. Time may have been a constraining factor for reproduction in experimental replicates as eggs isolated from sediments probably hatched a number of days earlier than those buried in sediments. Alternatively, toxicity or hypoxia caused by high biological oxygen demand of ballast sediments may have prevented reproduction in experimental replicates as the plankton mesh may have prevented adequate waterflow and oxygen renewal. If this is the case, this study may underestimate inoculum sizes as hatched organisms inside ballast tanks may initiate reproduction under more favourable abiotic conditions.

This study provides empirical support for the hypothesis that different life history characteristics may be beneficial during various stages of the invasion process. While dormancy is a characteristic enabling enhanced survival during transportation, it becomes a hindrance at the introduction stage, as less than $0.05 \%$ of individuals will likely pass from the transportation stage to the introduction stage under conditions experienced in ships' ballast tanks. In contrast, live planktonic animals probably have low survivability in ballast tanks but high opportunity for introduction with deballasting of water (see MacIsaac et al., 2002). As environmental and demographic stochasticity will further reduce the number of individuals successfully transitioning from the introduction stage (stage II) to the establishment stage (stage III) of the invasion process, the risk of invasion via diapausing eggs in residual ballast sediments appears very low. However, the assumption that the sediments and the resting stages contained therein are not being deposited directly into the Great Lakes, either during regular deballasting or tank cleaning operations, must be validated to ensure that this risk is not underestimated. Dry dock cleaning of sediments from ballast tanks should be carefully managed, as it can provide a direct route for discharge of diapausing eggs into adjacent bodies of water.

\section{ACKNOWLEDGEMENTS}

We thank Captain Philip T. Jenkins for his logistical support throughout this study, and Steve Constant for the construction of emergence traps and for field support. We are grateful for the cooperation and assistance provided by shipowners and operators, shipping agents, and vessel crews, without whom this study would not have been possible. Financial support from a National Science Engineering and Research Centre (NSERC) Industrial Postgraduate Scholarship, in partnership with the Shipping Federation of Canada to SAB, and an Invasive Species Research chair from DFO (Canada) to HJM are gratefully acknowledged. This work was conducted under the multi-institutional Great Lakes NOBOB Project funded by the Great Lakes Protection Fund, the National Oceanic and Atmospheric Administration (NOAA), the US Environmental Protection Agency, and the US Coast Guard. The project was co-managed by the Cooperative Institute of Limnology and Ecosystems Research and the NOAA Great Lakes Environmental Research Laboratory and sponsored under cooperative agreement NA17RJ1225 from the Office of Oceanic and Atmospheric Research, NOAA (GLERL contribution 1334).

\section{REFERENCES}

Bailey, S.A., Duggan, I.C., Jenkins, P.T. \& MacIsaac, H.J. (2005) Invertebrate resting stages in residual ballast sediment of transoceanic ships. Canadian Journal of Fisheries and Aquatic Sciences, in press. 
Bailey, S.A., Duggan, I.C., van Overdijk, C.D.A., Jenkins, P.T. \& MacIsaac, H.J. (2003) Viability of invertebrate diapausing eggs collected from residual ballast sediment. Limnology and Oceanography, 48, 1701-1710.

Bailey, S.A., Duggan, I.C., van Overdijk, C.D.A., Johengen, T.H., Reid, D.F. \& MacIsaac, H.J. (2004) Salinity tolerance of diapausing eggs of freshwater zooplankton. Freshwater Biology, 49, 286-295.

Burgess, R. (2001) An improved protocol for separating meiofauna from sediments using colloidal silica sols. Marine Ecology Progress Series, 214, 161-165.

Carlton, J.T. (1985) Transoceanic and interoceanic dispersal of coastal marine organisms: the biology of ballast water. Oceanography and Marine Biology: an Annual Review, 23, 313371.

Carlton, J.T. (2003) Community assembly and historical biogeography in the North Atlantic Ocean: the potential role of human-mediated dispersal vectors. Hydrobiologia, 503, 1-8.

Colautti, R.I., Grigorovich, I.A. \& MacIsaac, H.J. (2005) Propagule pressure: a null model for biological invasions. Biological Invasions, in press.

Colautti, R.I. \& MacIsaac, H.J. (2004) A neutral terminology for defining invasive species. Diversity and Distributions, 10, 135141.

Colautti, R.I., Niimi, A.J., van Overdijk, C.D.A., Mills, E.L., Holeck, K. \& MacIsaac, H.J. (2003) Spatial and temporal analysis of transoceanic shipping vectors to the Great Lakes. Invasion pathways: analysis of invasion patterns and pathway management (ed. by G.M. Ruiz, J.T. Carlton and R.N. Mack), pp. 227-246. Island Press, Washington, D.C.

Dermott, R. \& Munawar, M. (1992) A simple and sensitive assay for evaluation of sediment toxicity using Lumbriculus variegatus (Mueller). Hydrobiologia, 235-236, 407-414.

Drake, J.M. (2004) Allee effects and the risk of biological invasion. Risk Analysis, 24, 795-802.

Duncan, R.P., Blackburn, T.M. \& Sol, D. (2003) The ecology of bird introductions. Annual Review of Ecology and Systematics, 34, 71-98.

Elton, C.S. (1958) The ecology of invasions by animals and plants. Methuen, London.

Gollasch, S., MacDonald, E., Belson, S., Botnen, H., Christensen, J.T., Hamer, J.P., Houvenaghel, G., Jelmert, A., Lucas, I., Masson, D., McCollin, T., Olenin, S., Persson, A., Wallentinus, I., Wetsteyn, L.P.M.J. \& Wittling, T. (2002) Life in ballast tanks. Invasive aquatic species of Europe: distribution, impacts and management (ed. by E. Leppäkoski, S. Gollasch and S. Olenin), pp. 217-231. Kluwer Academic Publishers, Dordrecht.

Gray, D.K., Bailey, S.A., Duggan, I.C. \& MacIsaac, H.J. (2005) Viability of invertebrate diapausing eggs exposed to saltwater: implications for Great Lakes' ship ballast management. Biological Invasions, in press.

Grevstad, F.S. (1999) Factors influencing the chance of population establishment: implications for release strategies in biocontrol. Ecological Applications, 9, 1439-1447.

Grigorovich, I.A., Colautti, R.I., Mills, E.L., Holeck, K. \& MacIsaac, H.J. (2003) Ballast-mediated animal introductions in the Laurentian Great Lakes: retrospective and prospective analyses. Canadian Journal of Fisheries and Aquatic Sciences, 60, 740-756.

Grigorovich, I.A., MacIsaac, H.J., Shadrin, N.V. \& Mills, E.L. (2002) Patterns and mechanisms of aquatic invertebrate introductions in the Ponto-Caspian region. Canadian Journal of Fisheries and Aquatic Sciences, 59, 1189-1208.

Hayes, K.R. \& Sliwa, C. (2003) Identifying potential marine pests - a deductive approach applied to Australia. Marine Pollution Bulletin, 46, 91-98.

Holeck, K.T., Mills, E.L., MacIsaac, H.J., Dochoda, M.R., Colautti, R.I. \& Ricciardi, A. (2004) Bridging troubled waters: biological invasions, transoceanic shipping, and the Laurentian Great Lakes. Bioscience, 54, 919-929.

Kolar, C.S. \& Lodge, D.M. (2001) Progress in invasion biology: predicting invaders. Trends in Ecology and Evolution, 16, 199-204.

Kolar, C.S. \& Lodge, D.M. (2002) Ecological predictions and risk assessment for alien fishes in North America. Science, 298, 1233-1236.

Leppäkoski, E., Gollasch, S., Gruszka, P., Ojaveer, H., Olenin, S. \& Panov, V. (2002) The Baltic - a sea of invaders. Canadian Journal of Fisheries and Aquatic Sciences, 59, 1175-1188.

Lodge, D.M. (1993) Biological invasions: lessons for ecology. Trends in Ecology and Evolution, 8, 133-137.

MacIsaac, H.J., Robbins, T.C. \& Lewis, M.A. (2002) Modelling ships' ballast water as invasion threats to the Great Lakes. Canadian Journal of Fisheries and Aquatic Sciences, 59, 12451256.

Nebeker, A.V., Onjukka, S.T., Stevens, D.G., Chapman, G.A. \& Dominguez, S.E. (1992) Effects of low dissolved oxygen on survival, growth and reproduction of Daphnia, Hyalella, and Gammarus. Environmental Toxicology and Chemistry, 11, 373379.

Phipps, G.L., Mattson, V.R. \& Ankley, G.T. (1995) Relative sensitivity of 3 fresh water benthie macroinvertebrates to 10 contaminants. Archives of Environmental Contamination and Toxicology, 28, 281-286.

Pourriot, R. \& Rougier, C. (1997) Reproduction rates in relation to food concentration and temperature in three species of the genus Brachionus (Rotifera). Annales de Limnologie, 33, 23-31.

Putzer, V.M., de Zwann, A. \& Wieser, W. (1990) Anaerobic energy metabolism in the oligochaetes Lumbriculus variegatus Müller. Journal of Comparative Physiology Part B. Biochemical, Systematic, and Environmental Physiology, 159, 707-715.

Rouget, M. \& Richardson, D.M. (2003) Inferring process from pattern in plant invasions: a semi-mechanistic model incorporating propagule pressure and environmental factors. American Naturalist, 162, 713-724.

Ruiz, G.M., Fofonoff, P.W., Carlton, J.T., Wonham, M.J. \& Hines, A.H. (2000) Invasion of coastal marine communities in North America: apparent patterns, processes, and biases. Annual Review of Ecology and Systematics, 31, 481-531.

Sprague, J.B. (1963) Resistance of four freshwater crustaceans to lethal high temperature and low oxygen. Journal of the Fisheries Research Board of Canada, 20, 387-415. 


\section{S. A. Bailey et al.}

Taylor, B.E. (1988) Analysing population dynamics of zooplankton. Limnology and Oceanography, 33, 1266-1273.

Veltman, C.J., Nee, S. \& Crawley, M.J. (1996) Correlates of introduction success in exotic New Zealand birds. American Naturalist, 147, 542-557.

Wallace, R.L. \& Snell, T.W. (2001) Phylum Rotifera. Ecology and classification of North American freshwater invertebrates (ed. by
J.H. Thorp and A.P. Covich), pp. 195-254. Academic Press, San Diego.

Williamson, M. \& Fitter, A. (1996) The varying success of invaders. Ecology, 77, 1661-1666.

Wonham, M.J., Carlton, J.T., Ruiz, G.M. \& Smith, L.D. (2000) Fish and ships: relating dispersal frequency to success in biological invasions. Marine Biology, 136, 1111-1121. 